\title{
Cellular Automata Model of Urbanization in Camiguin, Philippines
}

\author{
Maria Isabel Beltran ${ }^{1}$ and Guido David ${ }^{2, \star}$ \\ 1 Sea Oil, Philippines \\ 2 Institute of Mathematics \& \\ Computational Science Research Center \\ University of the Philippines
}

\begin{abstract}
Monitoring and forecasting land use and change in the Philippines are necessary for urban planning, agricultural mapping, resource allocation and conservation. Land change studies are important in order to guide policymakers, government and private institutions. In this paper, 2-dimensional cellular automata using Markov chains is used to numerically simulate land change in Camiguin, an island province in the Philippines, over a period of 50 years. The preliminary findings of the study identify wooded areas that may be at risk of disappearing. The study also emphasizes the need for updated land cover data in the Philippines in order to improve land use forecasts.
\end{abstract}

Keywords: Cellular Automata, Markov chains, Monte Carlo simulation, land cover, maps.

\section{Introduction}

Since 1984, the Philippine population has been increasing at a rate of approximately $2 \%$ each year 1 . Roughly $13 \%$ of the national population live in the Metro Manila area 2]. Urbanization and development of the provincial regions of the Philippines, in part due to the flourishing tourism industry, would result in more people migrating to the provinces. Changes in land use are natural consequences of population growth. Cities have limited carrying capacity, and with time, more people would settle in neighboring areas. In this regard, it is important to study how land change could affect the nation's natural resources, including agriculture and forestry land. Grasslands are critical for farming and production of food resources, whereas forests and wooded areas preserve wildlife and endangered animal groups, and help control floods and reduce Carbon Dioxide in the atmosphere. Predicting how land is developed allows legislators to implement measures that may help prevent deforestation and maintain agricultural regions. Land cover simulations would also lead to improvements in strategic agriculture and mapping of farmlands to suitable crops. Moreover, land use

\footnotetext{
^ Corresponding author.
} 
studies would also provide a guide to long term urban planning. Hence it is necessary to conduct land change forecasts in order to anticipate future problems in urban and farm management, and to take necessary steps in correcting problems before they arise. Previous studies on land use in the Philippines have focused mainly on deforestation [3], and a much more comprehensive study on urbanization and farming allocation is needed.

Camiguin is an island province in the Philippines in the Mindanao region. It has an area of $237.95 \mathrm{~km}^{2}$, and a population of 83,800 (as of 2010 ) which has been growing annually at a rate of $1.22 \%$ [4. Its geographical features include volcanoes, waterfalls, and natural springs. It is home to a variety of aquatic habitats and corals. Camiguin has been advertised as a tourist destination for its beaches and diving attractions. In this study, a land development algorithm is implemented using Camiguin island as a model.

\section{Methods}

Two-dimensional cellular automata models have been used in analyzing transitions in land cover in other cities [5. Examples include land change use in Dongguan, Southern China [6] and in the Istanbul Metropolitan Area [7]. In a Cellular Automata model, each cell, corresponding to a unit area of land, is assigned one of four possible states, given here by:

1. water: seas and inland bodies of water

2. forests and wooded land

3. open land: agricultural land, pastures and barren land

4. built-up areas: developed areas, residential or commercial

Other studies have used more than four states by further reclassifying each group. For example, open land may be divided into barren land, cultivated land and pastures. A unit area of land may include more than one of the above, for example a region which has both barren land and built-up sections. In such cases, the state of the land region is simply the state that comprises majority of the area.

A Cellular Automata model provides transition rules that prescribe how one state may change to another state. Although Cellular Automata models are typically deterministic, the uncertainty of land change requires Markov matrices to account for probability-based transitions. At least two land images are needed in order to compute transition probabilities. Unfortunately, forestry data for the Philippines was only available for the year 2003. The transition matrix obtained from Istanbul [7] was used, given by the matrix $A$ below, which provided transition probabilities over an 11-year period.

$$
A=\left(\begin{array}{llll}
0.9967 & 0.0009 & 0.0017 & 0.0007 \\
0.0016 & 0.8850 & 0.1076 & 0.0058 \\
0.0135 & 0.0798 & 0.8590 & 0.0477 \\
0.0054 & 0.0008 & 0.0004 & 0.9934
\end{array}\right)
$$


By convention, the $A_{i j}$ entry of $A$ denotes the probability that state $i$ moves to state $j$ after 11 years. An assumption used here was that the rate of urban development in a region is linearly correlated with the population growth rate in the region. In Istanbul, the population grew 1.68\% annually. Over 11 years, this is roughly equivalent to 15 years under a growth rate of $1.22 \%$, the annual population growth rate in Camiguin. The one year transition matrix for modeling Camiguin was then obtained using $T=\exp (\log A / 15)$, where matrix logarithm and exponential was used. Due to the absence of inland water regions in the island, transitions from water to land or vice-versa were not considered. Thus,

$$
T=\left(\begin{array}{cccc}
1 & 0 & 0 & 0 \\
0 & 0.9916 & 0.0082 & 0.0002 \\
0 & 0.0061 & 0.9905 & 0.0034 \\
0 & 0.0001 & 0.0000 & 0.9999
\end{array}\right)
$$

The neighborhood of each cell was assumed to be a $9 \times 9$ Moore neighborhood, which included the 80 surrounding cells. This was roughly equivalent in area to the $5 \times 5$ neighborhood used in [7]. To obtain the actual one year transition probability for each cell, the following scheme was used:

$$
p_{i j}=\frac{w_{j} T_{i j}}{\sum_{k=1}^{4} w_{k} T_{i k}}
$$

where $i$ is the current state of the cell $(i=1,2,3,4), j$ is the target state $(j=1,2,3,4)$, and $w_{j}$ is the number of neighboring cells in state $j[8$. The assumption here was that the future state of a cell of land is affected by the present state of surrounding cells of land. For example, open land surrounding an isolated developed area was less likely to become developed than a piece of open area surrounded mostly by built-up areas of land.

\section{Results and Discussion}

An image map of Camiguin in 2003, obtained from [9], is shown in Figure 1 as a Matlabß image file, with blue indicating water, dark green indicating forests and wooded areas (with broad-leaved trees, shrubs or wooded grasslands), light green for open land (barren or with crops) and red for built-up areas (residential or factory). The image was equivalent to about $20 \mathrm{~km}$ along the vertical and $19 \mathrm{~km}$ along the horizontal. The land mass image was made up of 242,154 pixels, thus each pixel was equivalent to $982.64 \mathrm{~m}^{2}$, or a square piece of land $31 \mathrm{~m}$ on each side. The wooded areas comprised 101,388 pixels for a land cover of $99.63 \mathrm{~km}^{2}$, agricultural land comprised 137,986 pixels for a land cover of $135.59 \mathrm{~km}^{2}$, and built-up areas comprised 2,780 pixels, for a land cover of $2.73 \mathrm{~km}^{2}$. There were no inland water regions, and the coastline was assumed to be static. Changes in land cover after 20 years and 50 years are shown in Figures 2 and 3, respectively. Land development is a stochastic process, and random variations play a significant role in how land changes with time. Numerical forecasts are useful because 


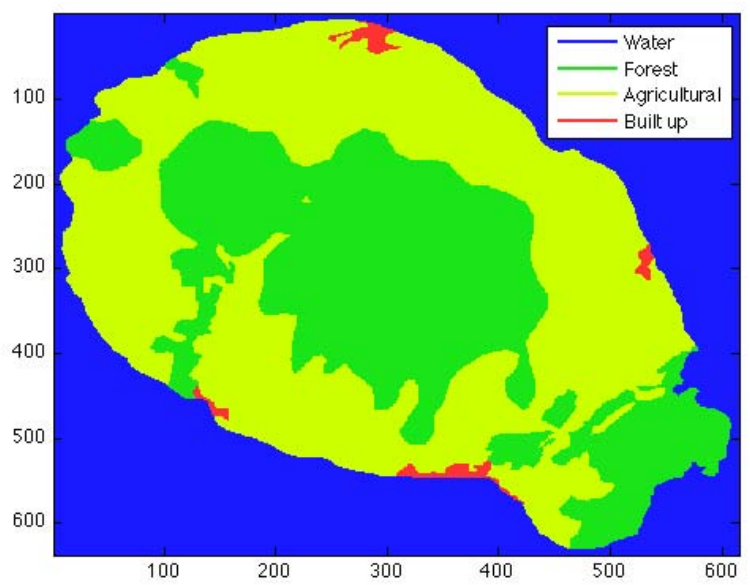

Fig. 1. Land cover of Camiguin, Philippines, based on 2003 data. Each pixel is equivalent to $982.64 \mathrm{~m}^{2}$. The box represents scaled dimensions of $19 \mathrm{~km} \times 20 \mathrm{~km}$.

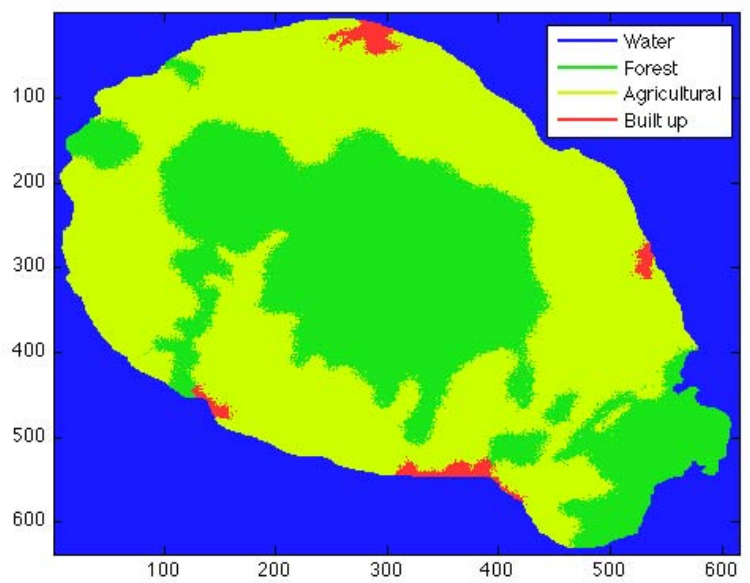

Fig. 2. Land cover of Camiguin, projected for 2023

they indicate likely trends in how land will develop in a geographical region. The forecast for 2023 (Figure 2) showed a 2.96\% increase in built-up land from 2003. Most of this increase was at the expense of agricultural land. However, agricultural land also had an increase of $1.46 \%$ from 2003 to 2023. Agricultural land that was lost due to development was replaced by wooded land that had transitioned to grasslands. As a result, wooded land decreased by $2.80 \%$ from 2003 to 2023. 
Longer term forecasts are causes for concern. According to Figure 3, in 2053, the built-up land would have increased by $263 \%$ from 2003. Most of this can be attributed to turnover of agricultural land. Agricultural land also increased by $4.39 \%$ due to conversion of wooded land. On the other hand, forests and wooded land decreased by $13.2 \%$. Some of the forests in the island of Camiguin, such as those near the south and southwest, would be in danger of disappearing.

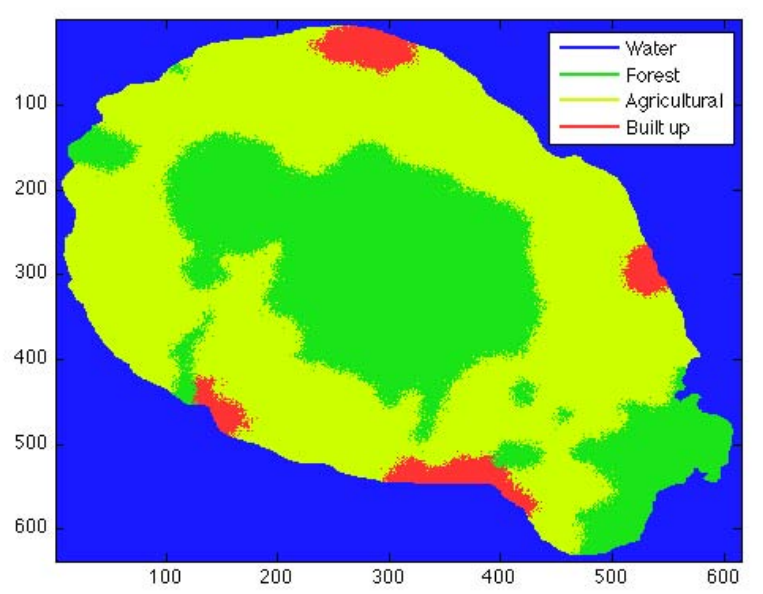

Fig. 3. Land cover of Camiguin, projected for 2053

\section{Conclusion}

A Markov-based cellular automata model of land change was used to numerically forecast land use in the island province of Camiguin. Land cover data in the Philippines was only available for 2003, and this served as a starting point for the simulations. With the lack of data, transition rates from Istanbul [7] were used. The Markov matrix was adjusted to match the population growth rate in the Philippines, assuming that urban development was proportional to population growth.

The results showed that in 2023, there would have been modest increases of $2.96 \%$ and $1.46 \%$ in built-up areas and agricultural land, respectively, while wooded land would have decreased by $2.80 \%$. By 2053, the built-up land would have increased by $263 \%$, agricultural land would have increased by $4.39 \%$ and wooded land would have decreased by $13.2 \%$. Such changes are significant and pose a threat to the existence of some wooded areas. Policymakers might be best advised to come up with laws if they wish to protect some of the endangered wooded areas. Land development is a natural result of the increasing population, and planning is needed for the proper management of the country's natural resources. 
In any mathematical model, long term forecasts should be regarded with caution. Firstly, the model incorporates randomness, hence forecasts only show some of the possible scenarios. Although the 50-year forecast may identify interesting trends and patterns, it is not as reliable as a shorter term forecast. Given a fixed geographic region, transition rates are not constant [7], and may vary significantly over long periods of time. Rates of development in Istanbul are likely to differ from those in the Philippines; even those from different regions in the Philippines are unlikely to be the same. Rates of urbanization are likely to be higher for regions that are moderately built-up, compared to areas that have few developments, such as isolated areas, or provinces that are close to saturation in terms of urbanization, e.g. big cities like Manila. Another limitation of the study is that elevation factors were not considered in transitions. Most of the wooded areas in the region are located in mountainous areas, thus it would be reasonable to assume that, compared with wooded areas in level land, the former would be less likely to become converted to open land.

The numerical results of the study serve as a guide for identifying land change patterns in Camiguin. The methods used herein may be applied to other regions in the Philippines, by adjusting the transition matrix to align with population growth rate, or obtaining transition values directly from data. The present study was made much simpler by the fact that Camiguin is an island province that is not directly affected by developments in its neighbors. This convenience is not possible for regions that are geographically connected. In such a case, the transition rates may also depend on the rate of development in neighboring regions, and adjustment factors would depend on available data. This study may also be expanded by using more land states, for example differentiating between wooded areas with broad-leaved trees, shrubs and grasslands. As more land use data becomes available, the specific classification of lands, as well as more precise transitions may be used to improve the cellular automata forecasts of land change. This would lead to more reliable forecasts of land cover in the Philippines.

Acknowledgments. This project was supported by the University of the Philippines Research and Creative Work Program and Neuroworks Inc.

\section{References}

1. David, G., Gomez, F.: Sexuality-based compartmental model of spread of HIV in the Philippines. Philippine Science Letters 7(1), 62-66 (2014)

2. The World Factbook 2013-14. Central Intelligence Agency, Washington, DC (2013), https://www.cia.gov/library/publications/the-world-factbook/index.html (retrieved from)

3. Verburg, P.H., Veldkamp, A.: Projecting land use transitions at forest fringes in the Philippines at two spatial scales. Landscape Ecology 19, 77-98 (2004)

4. Ericta, C.N.: 2010 Census of Population and Housing. National Statistics Office, Philippines (2010), http://www.census.gov.ph/statistics/census/population-and-housing (retrieved from) 
5. O'Sullivan, D., Torrens, P.: Cellular automata and urban simulation: Where do we go from here? Environment and Planning B: Planning and Design 28, 163-168 (2007)

6. Li, X., Yeh, A.: Neural network-based cellular automata for simulating multiple land use changes using gis. International Journal of Geographical Information Science 16(4), 323-343 (2002)

7. Demirel, H., Cetin, M.: Modelling urban dynamics via cellular automata. ISPRS Archive 38(pt. 4-8-2-W9), 199-203 (2010)

8. Beltran, M.I.: A cellular automata model for land development and urbanization. Undergraduate Research Paper, University of the Philippines (2013)

9. Forest Management Bureau, Forest Cover, DENR, Quezon City, Philippines (2003), http://forestry.denr.gov.ph/landusereg.htm (retrieved from) 